\title{
EDITORIAL
}

\section{What qualifies a person to be an author of a research paper?}

José Eymard H. Pittella'; Adagmar Andriolo²; Alfredo José Afonso Barbosa³; Silvana Maria Eloi Santos ${ }^{4}$

This question is the initial sentence of an editorial published in the prestigious British Medical Journal in $2011^{(1)}$. Perhaps satisfactory answers to the complex questions concerning authorship are not feasible, desirable or even possible. But most researchers would agree that transparency in the attribution of authorship on a scientific paper must be an estimable and valuable goal. The growing pressure to produce curricula vitae rich in publications - due to the increased competition for research grants, funding for science projects and academic promotion - has caused, since the last decades of the twentieth century, a dramatic spread of publications with numerous authors. There are many good reasons to list multiple authors, especially in the case of cooperative research studies performed at several institutions. However, the steady increase of multi-authored activity in science has led to an escalation of disputes concerning authorship and co-authorship acknowledgement in scientific research ${ }^{(2,4,5)}$. This happens mostly because researchers do not demonstrate clarity and sincerity on the subject when discussing a project. They define neither participants' roles and expectations, nor the order of names on the byline. The disputes quite frequently reveal a power struggle among researchers; when unsettled, may be a source of conflict and divert the academic and scientific purposes of a study. Besides, they may affect resource allocation for new works.

In an effort to decide the complex issue of multiple authorship and disputes over authorship, internationally recognized rules have been proposed, and authors should be aware of them when submitting papers for publication. These guidelines were initially drawn up by a small group of North-American and British general medical journal editors. They became known as the Vancouver Group because their first meeting was held in that Canadian city, in 1978, and they published the first edition of the guidelines (Uniform requirements for manuscripts submitted to biomedical journals [URMs]) the following year. The Vancouver Group eventually expanded and became the International Committee of Medical Journal Editors (ICMJE), engaged in periodically updating URMs ${ }^{(3)}$. Recommendations for the conduct, reporting, editing, and publication of scholarly work in medical journals were published; the last revision was released in 2013.

This committee prepared specific instructions for authors (see topic "Defining the role of authors and contributors"). According to them, designation as an author must be validated for: a) conception and design of the study, or analysis and interpretation of data; b) drafting of the article or critical revision of its content; c) final approval of the version to be published; d) responsibility for all the aspects of the work, ensuring that questions related to accuracy or integrity of any part of it are adequately investigated and analyzed. All authors listed in the paper must meet the four criteria, and participants that do not meet them must be acknowledged. For example, participation in the acquisition of funding or the collection of data alone does not justify authorship; general supervision of the research group does not either. Similarly, the head of the department where the research was carried out - in case he was not directly involved in the work -, and physicians and technicians who collaborated with routine services or technical support should not be granted authorship.

1. Pathology section associate editor at Jornal Brasileiro de Patologia e Medicina Laboratorial (JBPML).

2. Editor-in-chief at JBPML.

3. Pathology section editor at JBPML.

4. Laboratory Medicine section editor at JBPML. 
These criteria are not supposed to be used as a means to disqualify colleagues from authorship when they have cooperated just, for instance, in data collection, analysis and interpretation. The committee recommends that, in this situation, authors identify these colleagues and give them opportunity to participate in the other steps of design and development of the study. It is collective responsibility of the authors, and not of the journal to which the work is submitted, to determine that all individuals identified as authors satisfy the aforementioned criteria. Editors and reviewers, in their turn, are responsible and participate in the following phases of the submission process: a) select manuscripts presented for publication; b) exclude poor-quality studies, with irrelevant content; c) enhance the quality of a paper, detecting errors and omissions, and suggesting alternative questions and explanations, besides ensuring accuracy, validity and reliability of the published data. It is not the duty of journal editors to say who qualifies for authorship or to arbitrate authorship conflicts. The institution where the work was conducted must be questioned instead. Furthermore, whenever authors request removal or addition of an author's name after manuscript submission or publication, the journal editors must obtain an explanation and a statement of agreement for the requested alteration, signed by all the authors and by the author who had his name removed or added.

In order to help solve this complex issue on multiple authorship and authorship disputes, some medical journals like Lancet, British Medical Journal and Annals of Internal Medicine started to require a form detailing what contribution each author made to the manuscript. Each one's role is then inserted in a footnote or at the end of the published article, disclosing his or her specific participation in one or more stages of the work. This decision was based on the concept of "contribution", as defined by its originator: "contribution is the activity of science that is most relevant to publication because its disclosure can identify who is accountable for what part of the research and allows the reader to assign credit fairly"(5). The idea of contributor is more in line with the collaborative work currently existing in science. Its validity, indeed, may be assessed by the high number of journals that started to adopt this practice.

\section{REFERENCES}

1. BASKIN, P. K.; GROSS, R. A. Honorary and ghost authorship has not substantially declined, suggesting that standards need tightening up. $B M J$, v. 343, p. d6223, 2011.

2. BIAGIOLI, M. The instability of authorship: credit and responsibility in contemporary biomedicine. FASEB Journal, v. 12, n. 1, p. 3-16, 1998.

3. INTERNATIONAL Committee of Medical Journal Editors. [homepage on the internet]. Recommendations for the conduct, reporting, editing and publication of scholarly work in medical journals. Available at: <http://www.icmje.org > . Accessed on: Jan. 28, 2014.

4. PITTELLA, J. E. Construindo o saber da ciência. Belo Horizonte, MG: Coopmed, 2012.

5. RENNIE, D.; YANK, V.; EMANUEL, L. When authorship fails: a proposal to make contributors accountable.JAMA, v. 278, n. 7, p. 579-85, 1997. 